\title{
PRÁTICAS DE CO-AUTORIA NO PROCESSO DE COMUNICAÇÃO CIENTÍFICA NA PÓS- GRADUAÇÃO EM CIÊNCIA DA INFORMAÇÃO NO BRASIL
}

\section{PRÁCTICAS DE COAUTORÍA EN EL PROCESO DE COMUNICACIÓN CIENTÍFICA EN CIENCIA DE LA INFORMACIÓN EN BRASIL}

\author{
Leilah Santiago Bufrem - leilah@ufpr.br \\ Doutora em Ciências da Comunicação e Pós-Doutora em Documentação \\ Professora Titular do Departamento de Ciência e Gestão da Informação, \\ Universidade Federal do Paraná, UFPR
}

\begin{abstract}
Rene Faustino Gabriel Junior - rene@sisdoc.com.br Mestrando em Ciência, Gestão e Tecnologia da Informação, Universidade Federal do Paraná, UFPR
\end{abstract}

Viviane Gonçalves - viviane.goncalves@pucpr.br Mestranda em Ciência, Gestão e Tecnologia da Informação, Universidade Federal do Paraná, UFPR

\begin{abstract}
Resumo
Analisa diacronicamente 20 anos (1990-2009) de produção científica dos pesquisadores vinculados aos Programas de Pós-Graduação stricto sensu em Ciência da Informação no Brasil enfocando a produção em co-autoria. Constitui corpus específico, com o levantamento dos artigos brasileiros científicos da área relacionados com o tema comunicação científica, dando ênfase especial à co-autoria. Realiza análise empírica sobre a produção dos pesquisadores, levantada nos currículos Lattes, especificando as ocorrências de co-autoria na produção de livros, capítulos de livros, artigos em revistas científicas e trabalhos completos em eventos. Apresenta os resultados da análise de 12.072 trabalhos científicos de 156 pesquisadores para evidenciar a trajetória do processo evolutivo de produção em co-autoria nas publicações da área, identificando crescimento e expansão da produção em co-autoria, ainda em evolução.
\end{abstract}

\section{Palavras-chave}

Comunicação da ciência. Comunicação científica. Ciência da Informação. Co-autoria. 


\section{INTRODUÇÃO}

Considerando-se que a ciência é um conjunto de práticas socialmente construídas na tentativa de descobrir progressivamente as estruturas causais da realidade, como Lloyd (1995) afirma, pode-se estabelecer critérios de cientificidade. Entre eles, destaca-se, para este estudo, o conjunto de condições e práticas para que se efetive a comunicação da produção científica. Esta precisa ser analisada e compreendida em tal evolução e por meio de tais práticas, uma vez que este tipo de comunicação favorece a visibilidade da produção. Como conseqüência, ocorrem a validação e a credibilidade da construção científica (TARGINO, 2000).

A comunicação científica resulta dos avanços nas formas de institucionalização científica. Para Whitley (1974), esta institucionalização apresenta duas dimensões. Uma delas, cognitiva, sustentada por conceitos, teorias, problemas, métodos, leis e técnicas, próprios de uma ciência. A outra, de caráter social, relativa à criação de instituições formais representativas da ciência, tais como livros e revistas científicas, sociedades científicas, cursos de graduação e de pós-graduação, grupos de pesquisa e eventos. Relacionadas dinamicamente, essas dimensões impulsionam e são impulsionadas por uma conjuntura favorável à comunicação científica. Embora a conjuntura diversifiquese de acordo com cada um dos campos científicos autônomos, as dimensões social e cognitiva (de cada um dos campos) relacionam-se com as formas mais ou menos padronizadas de comunicação científica.

A comunicação científica faz parte da dimensão social da institucionalização de uma ciência, tanto em relação ao que Whitley (1974) denominaria de organização interna quanto ao grau de integração dentro da estrutura social, em termos de legitimação dos conhecimentos e das práticas, e da alocação de recursos.

Importa salientar que o trabalho científico e seus resultados, em determinado contexto social e momento histórico, refletem mudanças e contradições do contexto, tanto em sua forma de organização interna quanto em seus modos de comunicação e de divulgação. Assim, as condições socioeconômicas e a vontade política das instâncias de poder podem incrementar ou cercear atividades ou processos de comunicação científica. Aliada aos imperativos da produção, na conjuntura em que atua, a política de comunicação científica mobiliza recursos no interesse do aumento constante da produção, de modo geral, ou em direção a determinada área ou setor especificamente.

Neste caso, a ciência que se produz e se comunica constitui instrumento privilegiado de legitimação de poder, uma vez que é mobilizada como força produtiva para determinados propósitos. Por sua vez, a comunicação científica, em sua condição de mediadora de informações relevantes para a ampliação do conhecimento, pode desempenhar papel ideológico, desde que regida por critérios que contribuam para legitimar e reproduzir as relações de poder presentes na sociedade. Se o poder hegemônico se exerce nas formas de comunicação científica, na medida em que restringe a utilização sistemática do conhecimento científico registrado, é necessário desvendar as formas de 
legitimação e de reforço desse poder também nas expressões formais e nos modelos que o reproduzem.

Esta reflexão apóia-se, também, nas concepções de Ladrière (1978), para quem a ciência age sobre a realidade, transformando-a, sobretudo por meio da face visível de suas produções. Esta face permite a tarefa crítica à prática, no sentido de que sejam aperfeiçoados os procedimentos e as formas, não somente de produção, mas de comunicação da produção. O propósito inclui compreensão e ampliação das investigações situadas em corpora que se concretizam historicamente.

A compreensão das mudanças e das contradições desse contexto, tanto em sua forma de organização interna quanto em seus modos de comunicação e divulgação, carece de análise e interpretação das estruturas da comunicação científica existentes. Com o objetivo de analisar a co-autoria na produção científica dos pesquisadores vinculados aos Programas de Pós-Graduação em Ciência da Informação (PPGCl) no Brasil, este estudo desdobra-se em duas etapas. A primeira volta-se à constituição de um corpus específico, com o levantamento dos artigos científicos da área, relacionados com o tema comunicação científica, dando ênfase especial à co-autoria. A segunda etapa concretiza-se em análise empírica dos curricula vitae dos pesquisadores de pósgraduação em $\mathrm{Cl}(\mathrm{PGCl})$, no Brasil, mantidos na Plataforma Lattes, base de dados de currículos e de instituições das áreas de ciência e tecnologia (C\&T), sob a responsabilidade do Conselho Nacional de Desenvolvimento Científico e Tecnológico (CNPq), quando é possível identificar as relações de co-autoria em suas produções.

Como foco deste trabalho, a co-autoria destaca-se entre as modalidades de comunicação científica, analisada empiricamente de acordo com a trajetória:

1. Contextualização do tema na literatura nacional, representada na Base Brapci, com foco na co-autoria. Trata-se de base de dados referenciais de periódicos / revistas nacionais em $\mathrm{Cl}$, organizada e atualizada pelo Grupo de Pesquisa em Educação, Pesquisa e Perfil Profissional do CNPq.

2. Recorte empírico de estudos em co-autoria da PGCl, no Brasil, entre 1990 e 2009.

3. Análise dos tipos de comunicação científica em co-autoria.

4. Análise diacrônica da produção científica em co-autoria na área.

A utilização da publicação periódica na primeira fase do trabalho leva em conta que este tipo de informação é fundamental para a identificação de conteúdos relevantes sobre o tema, além do que, resulta de produções avaliadas e aprovadas pelos pares e por instituições de pesquisa e comitês editoriais. A análise da literatura não foi exaustiva, mas procurou identificar os principais trabalhos publicados sobre o tema co-autoria. Além do mais, levou-se em consideração a participação dos pesquisadores atualmente vinculados aos 12 PPGCl, sendo 11 disciplinares e um multidisciplinar. Os tipos de comunicação científica considerados para o estudo foram livros, capítulos de livros, artigos de 
periódicos e comunicações em eventos com textos completos. Por definição, são considerados e tipificados como trabalhos em co-autoria aqueles com dois autores ou mais.

A escolha dos Programas de Pós-Graduação para o estudo empírico parte do pressuposto de que a universidade é o lócus por excelência da produção científica, uma vez que não estabelece fronteiras aos processos de comunicação. Ao contrário, favorece, por meio de relações interinstitucionais, laços e pontes de comunicação e de produção do saber.

Para a realização da análise diacrônica da produção científica em coautoria em $\mathrm{Cl}$, foram construídos gráficos sobre a produção, destacando-se como evoluíram as variáveis relacionadas ao tipo de comunicação e à quantidade de autores dos artigos.

Este estudo está permeado pela convicção de que a pesquisa pode ser considerada um meio de conhecimento, integradora de teoria e prática, e sua comunicação decorre da consciência da necessidade de ampliação do universo de leitores ao alcance dos quais estaria o saber constituído. O arcabouço de saberes registrados, por sua vez, enseja reflexão sobre a representação das relações que configuram o domínio científico.

\section{COMUNICACCÃO CIENTÍFICA NA LITERATURA EM CÊNCIA DA INFORMAÇÄO, BRASIL}

A primeira constatação oriunda deste estudo é o reconhecimento da comunicação científica como elemento indispensável para que se complete o processo de renovação do conhecimento. Considerado por Oliveira e Ferreira (2009) como elemento fundamental para a vida em sociedade e para a construção da ciência, o conhecimento depende da informação e, conseqüentemente, de sua comunicação, formal ou informal. Este fluxo beneficia tanto os que produzem informação quanto os que a consomem. Logo, além da produção do conhecimento, é fundamental sua publicação e validação pela comunidade científica. Esta comunidade é vista como importante indicador da produção de qualquer campo do conhecimento, pois possibilita verificação e análise da comunidade científica na qual foi realizada.

Os estudos em comunicação científica constituem uma das correntes teóricas apresentadas por Araújo (2009), dentre outras categorias, como estudos de natureza matemática, teoria sistêmica, teoria crítica, teorias da representação e estudos de usuários. O autor analisa o conceito de informação em cada uma das teorias citadas e identifica como, historicamente, contribuíram para consolidar um paradigma positivista para o campo.

Em revisão sobre o tema comunicação científica e tecnológica no Brasil, Mueller (2008) analisa as tendências e perspectivas na área de $\mathrm{Cl}$, em artigos publicados no período entre 2000 e julho de 2008 em seis revistas, na tentativa de identificar temas freqüentes, métodos adotados, tendências teóricas e preocupações emergentes. Os resultados indicam predominância de estudos baseados no periódico / na revista e artigo científico e de técnicas bibliométricas nos estudos quantitativos, com pouca incidência do emprego de metodologias 
mistas. Ainda que não explícita, percebe-se a predominância da visão mertoniana da ciência nos estudos da área.

Para melhor compreensão do ciclo de comunicação científica, Noronha e Maricato (2008) apresentam conceitos e considerações fundamentais dos estudos métricos da informação e os principais métodos e técnicas utilizados, como bibliometria, cienciometria, informetria, webmetria, patentometria e biblioteconometria. Destacam os principais indicadores de input (insumo) e output (produto), assim como a importância da publicação dos resultados da pesquisa científica e da avaliação pelos pares, comentando características e aplicações das leis bibliométricas e de outros recursos utilizados nos estudos métricos da informação.

A comunicação científica, o periódico científico e o incremento do acesso à informação e à comunicação pelas redes eletrônicas introduzem a discussão da relação da comunicação com a divulgação científica. A ampliação da audiência proporcionada pela internet e a maior visibilidade da ciência com a versão eletrônica dos títulos científicos são exploradas por Valerio e Pinheiro (2008), que discutem a aproximação entre público especializado e não especializado, bem como a possível convergência de audiências a partir da comunicação em redes eletrônicas via tecnologias de informação e de comunicação (TIC). As transformações tecnológicas sugerem alteração de práticas culturais na produção e na disseminação da informação.

Esta mudança de cultura resulta das transformações provocadas pelas tecnologias no ciclo de comunicação científica, em especial, com a emergência da internet, como Bertin (2008) analisa, sob perspectiva histórica, ao longo dos últimos 20 anos. A fase evolucionária inicial seguiu a emergência dos primeiros jornais digitais e a criação de repositórios na web para publicação de versões preliminares de trabalhos por iniciativa do próprio autor. De 1996 em diante, na fase de consolidação, os jornais eletrônicos, comumente, consistiam em cópias idênticas das versões impressas. A aceitação do formato eletrônico se expandiu, e os serviços de preprints se disseminaram. A fase evolucionária avançada iniciou-se com a discussão mundial sobre o acesso livre à informação. A comparação do jornal eletrônico corrente com aquele imaginado pelos entusiastas nos primeiros anos da década de 90 mostra alguns aspectos a serem aperfeiçoados na comunicação, em vista de efetiva disseminação da informação científica.

Os repositórios digitais vêm sendo considerados ferramentas para a promoção da comunicação científica. Ao disponibilizarem produtos de pesquisas científicas de maneira gratuita e não burocrática, facilitam o acesso às informações de caráter acadêmico. Ribeiro e Vidotti (2009) defendem os benefícios do uso dos repositórios digitais, principalmente em universidades, considerando que, além da proposta de acesso livre à informação, as instituições mantenedoras devem observar elementos que garantam, de fato, o acesso ao conteúdo apresentado.

Outros autores, a exemplo de Bomfá et al. (2008); Costa (2008); e Swan (2008) privilegiam o acesso livre à informação. Apresentam os principais movimentos nacionais e internacionais prol acesso livre e identificam repositórios de pesquisas científicas baseados nesses movimentos, além de discutirem 
dificuldades e tendências. Sinalizam mudanças na comunicação científica, com ênfase na amplitude, rapidez e transparência possíveis no acesso livre à informação científica (BOMFÁ et al., 2008). Afinal, o conhecimento científicotecnológico oriundo de pesquisas visa solucionar problemas da sociedade e contribuir para seu desenvolvimento, conforme argumentam Barbosa e Silva e Silva (2009), que analisam a comunicação científica, por meio de canais formais e / ou informais.

Ao tratar de questões relativas aos impactos oriundos da Open Archives Initiative (Iniciativa dos Arquivos Abertos, OAI) sobre as comunidades científicas no mundo inteiro, Alves (2008) constata as mudanças ocorridas no cenário da comunicação científica. São transformações com vistas ao acesso livre e gratuito da produção registrada, e, ainda, ao respeito aos direitos autorais e à autorização de uso do material disponibilizado.

De fato, a evolução das TIC garante à comunicação dinamismo ampliado com as apropriações sociais da web 2.0, que lançam novos olhares para a produção e a difusão científica e cultural. O exemplo analisado por Argollo et al. (2010) é a plataforma de escrita colaborativa TWiki, utilizada pelo Grupo de Pesquisa Educação, Comunicação e Tecnologias (GEC / Faculdade de Educação / Universidade Federal da Bahia). Alguns aspectos emergem das práticas de produção e difusão, como a autoria colaborativa, os licenciamentos (Creative Commons), as arquiteturas de participação e a reconfiguração - quando os sujeitos sociais passam de receptores para produtores e difusores de sua própria produção.

As arquiteturas de participação que envolvem sujeitos produtores e comunicadores estimulam e promovem a intensificação do uso das tecnologias interativas em Rede. Amplia-se, assim, o atual cenário de produção e de comunicação científica com a conseqüente diversificação dos atores, como analisa Moura (2009), ao estudar o intercâmbio de funções e a relativa horizontalização das relações sociais na produção científica. Discutindo os aspectos sociais e tecnológicos envolvidos nas novas dinâmicas de cooperação científica on-line, a autora apresenta as concepções de comunidades de prática, comunidades virtuais de prática e de redes sociais, assim como seu entrelaçamento na dinâmica de compartilhamento de informação e de conhecimento.

A preocupação com a qualidade da produção científica em qualquer área do conhecimento reflete-se nas modalidades específicas para divulgá-lo. Estudos, como o de Duarte et al. (2009), apresentam as estratégias metodológicas adotadas nas pesquisas de iniciação científica premiadas na Universidade Federal da Paraíba.

Os eventos científicos, assim como as revistas, são meios eficientes de comunicação do conhecimento. Estudos de avaliações científicas realizadas no Brasil constatam a representatividade desses canais para a divulgação da ciência. Ohira e Ohira (2008) analisam estudos de produção científica publicados na literatura, realizados a partir da análise das comunicações apresentadas desde a primeira edição do Seminário Nacional de Bibliotecas Universitárias (SNBU), identificando variáveis, o comportamento e as especificidades de tal produção. 
Os relatórios também são reconhecidos como potenciais instrumentos de comunicação, como mostra o trabalho de González de Gómez e Machado (2007), sobre questões de acesso à informação científica. Para dar visibilidade à produção científica cinzenta gerada em instituições de pesquisa e, em especial, os relatórios de pesquisa, o estudo analisa o papel e a importância dos relatórios de pesquisa para investigadores que trabalham nessas instituições, por meio de estudo de caso no Instituto de Comunicação e Informação Científica e Tecnológica em Saúde da Fundação Oswaldo Cruz (ICICT / FIOCRUZ).

O ciclo de produção do conhecimento científico que se efetiva entre os processos de recuperação da informação e a publicização dos resultados de pesquisa, entretanto, é criticado por Caxias (2008). O autor chama a atenção para um discurso instrumentalizado, decorrente de imposições oriundas de políticas públicas e de uma cultura de agilização forjada pelos novos mecanismos tecnológicos, transformando a produção de conhecimento num movimento publicacionista.

$\mathrm{Na}$ verdade, grupos de pesquisa e sua produção têm sido objeto de estudos, sobretudo, nas duas últimas décadas. Resultados de investigação financiada pelo CNPq identificam 103 grupos de pesquisa em $\mathrm{Cl}$, cadastrados no Diretório dos Grupos de Pesquisa da agência, ano 2004. De posse dos dados obtidos, constatou-se que esses grupos, integrados por doutores, mestres e bolsistas de iniciação científica, cujos perfis concentram-se em bibliotecários com $\mathrm{PCl}$, não estão bem distribuídos, com concentração no Sudeste e no Sul do País. Há participação de graduados em outras áreas, mas sempre com pós-graduação em Ciência da Informação (OLIVEIRA, 2009).

\section{CO-AUTORIA NA COMUNICAÇÃO CIENTÍFICA}

Um amplo espectro de possibilidades de estudos sobre co-autoria é encontrado na literatura. Há aqueles voltados às questões metodológicas, como o de Savanur e Srikanth (2009), que propõem modificação no coeficiente de colaboração (CC), uma medida que reflete tanto o número médio de autores por artigo como a proporção de artigos de autoria múltipla, denominada Modified Collaboration Coefficient (MCC). Há aqueles estudos aplicados a realidades específicas, nos diversos níveis em que se concretizam. Por meio de avaliações, hoje facilitadas com o uso de recursos tecnológicos de ponta, pode-se garantir maior precisão e objetividade aos estudos sobre características, tendências e motivações da produção científica. Tal conjuntura, aliada à análise de indicadores, revela, por sua vez, uma economia de trocas simbólicas (BOURDIEU, 1976) e uma estrutura de relações de produção e de poder, na qual instrumentos de avaliação objetiva podem indicar tendências, esclarecer razões, determinações e fatores que influenciam a atividade e o capital científicos.

O potencial da aplicação de parâmetros bibliométricos na avaliação tem pautado estudos e relatos sobre indicadores de C\&T voltados aos fatores, como a intensificação da colaboração científica e o impacto de citações. Isto ocorre, conforme Persson e Glänzel e Danell (2004) argumentam, em todos os campos e em todos os níveis de agregação, sugerindo a construção de indicadores aplicados às análises de tendências e estudos baseados em observações de 
médio e longo prazo para garantir a validade de conclusões retiradas de resultados bibliométricos.

De acordo com Meadows (1999), as pesquisas em colaboração têm maior visibilidade, levando em conta o número de citações que recebem, e tendem a ser de melhor qualidade, pois, em geral, envolvem cientistas produtivos e de renome, o que estimula a maturação mais consistente das idéias.

Quanto aos resultados da colaboração na produção intelectual, Lee e Bozeman (2005), acreditando na importância do entendimento dos fatores individuais e ambientais para explorar o potencial de seus benefícios, analisam os sujeitos pesquisadores e o ambiente de trabalho de centros de pesquisa universitários nos Estados Unidos da América. Concluem, então, que a freqüência absoluta de artigos em periódicos está fortemente associada ao número de colaboradores, sendo perceptíveis os efeitos significativos de bolsas de pesquisa, cidadania, estratégias de colaboração e campo científico.

Aplicando indicadores de co-autoria a realidades, como grupos de pesquisa, revistas e áreas científicas, estudos coordenados por Nederhof, em colaboração com Zwaan e De Bruin e Dekker (1989); Zwaan (1991); Noyons (1992); Meijer e Moed e Van Raan (1993); Moed (1993); e, também, com Van Raan (1993) estabelecem, discutem, avaliam e comparam resultados concretos.

Deste modo, a criação e a organização de indicadores e de sua integração em um sistema de "contabilidade" (VELHO, 1986) vêm contribuindo para a compreensão das relações que se estabelecem entre autores, destes entre si e entre instituições e países. Destacam-se as medidas de co-autoria que, além de representarem interação entre duas ou mais pessoas (KATZ; MARTIN, 1997), revelam aproximações entre autores e instituições, relacionando-os também com domínios temáticos e posições geográficas. Entre outras variáveis determinadas pelas relações de co-autoria, merecem menção redução de custos e multidisciplinaridade (LETA; CRUZ, 2003). Pode-se afirmar, portanto, que a colaboração científica, como a concebem Weisz e Roco (1996), em sua condição de empreendimento cooperativo, envolve metas comuns, esforço coordenado e resultados ou produtos (trabalhos científicos) com responsabilidade e mérito compartilhados. Assim, oferece fonte de apoio para melhorar o resultado e maximizar o potencial da produção científica.

Voltando-se aos indicadores de colaboração internacional, De Lange e Glänzel (1997) apresentam modelo de análise bibliométrica, uma generalização da abordagem por fracionamento de Nederhof e Moed (1993). Propõem uma medida, além do Multilateral Collaboration Index, para análise detalhada da distribuição da colaboração internacional, aliada ao crescimento substancial de textos multinacionais, envolvendo três ou mais países, a partir dos anos 90.

Em outro estudo do gênero, Sancho et al. (2006) apresentam indicadores de colaboração científica de 24 países da América Latina e do Caribe. São advindos de artigos firmados por autores de duas ou mais entidades, em revistas científicas de difusão internacional, mostrando que os países mais produtivos em ciência apresentam colaboração relativamente menor do que os pequenos produtores, numa conjuntura em que se percebe evolução positiva dos hábitos de colaboração internacional. 
Em relatório para a Commission of the European Communities, a $\mathrm{CHI}$ Research Inc. desenvolveu indicadores para o National Science Board's Science Indicators Reports, dando início aos Science Indicators, em 1972. O relato descreve como, ampliadas as tecnologias e as bases de dados dos indicadores científicos, analisaram a co-autoria e a citação em 28 campos científicos de programas da União Européia, anteriormente designada por Comunidade Econômica Européia. Indica, então, que os artigos em co-autoria têm maior impacto nas citações e que este tipo de autoria internacional cresce, evidenciando a força de fatores linguísticos, históricos e culturais (NARIN; STEVENS; WHITLOW, 1991).

Outros trabalhos sobre co-autoria também mostram razões geográficas, além das já citadas, pautando a colaboração científica entre nações (CUMBERS; MACKINNON; CHAPMAN, 2003; MATTHIESSEN; SCHWARZ; FIND, 2002; ZITT; BASSECOULARD; OKUBO, 2000). Também sob esta ótica, Vanz (2009) e Vanz e Stumpf (2009) discutiram a co-autoria em artigos em colaboração internacional produzidos por autores brasileiros e indexados nos bancos de dados do Science Citation Index (SCI) do Institute for Scientific Information (ISI, Thomsom Scientific), entre 2004 e 2006. O agrupamento em redes reflete colégios invisíveis entre os cientistas e a forma de interação mostra variações conforme os fatores determinantes da co-autoria. Motivos e formatos diferenciados de colaboração também são focados por Beaver (2001), cuja análise metodológica sugere caminhos para pesquisas futuras, baseadas em visão de passado e presente e nos problemas enfrentados.

Estudos comparativos sobre produção científica distinguem-se nos últimos anos. É o caso do trabalho de Russell e Del Río e Cortés (2007) sobre a visibilidade internacional da pesquisa científica, em artigos publicados nos títulos interdisciplinares Nature e Science, de 1973 a 2005. Como essas pesquisas, outras revelam a relevância dos indicadores levantados em bases de dados internacionais para monitorar a produção científica individual ou coletiva em todos os níveis de abrangência, possibilitando estimativa de como pesquisador, instituição ou país contribui para o avanço científico no cenário local ou internacional.

Destacam-se, na literatura periódica, estudos sobre co-autoria, confirmando sua posição como indicador de colaboração científica. Argañaraz e Sosa e Rapela (2003) analisaram projetos de pesquisa aprovados pela Secretaría de Ciencia y Tecnología de la Universidad Nacional de Córdoba, durante o período 1996 a 1999, como amostra de produtividade, observável com a aplicação de leis bibliométricas à análise da produção de 14 unidades acadêmicas. Entre outras contribuições significativas, a pesquisa constata que prevalece a autoria múltipla na produção e que a uma maior colaboração dos autores mais ativos corresponde uma menor produtividade fracionária.

Ao observarem os fatores que influenciam as relações de colaboração científica de uma atividade de pesquisa multidisciplinar - a área de bioprospecção - como afinidades econômicas, culturais e geográficas, Lima e Velho e Faria (2007) apresentam indicadores bibliométricos de co-autoria que abrangem de 1986 a 2006, computados a partir da base bibliográfica internacional e multidisciplinar, SCl. Foresti e Martins (1987), por sua vez, discutiram a produtividade de autores de artigos de quatro revistas brasileiras de 
Biblioteconomia, Documentação e Cl, entre 1980 e 1985. Verificaram a incidência de novos autores mais produtivos no período e a permanência de autores dos anos 70 , dedicados, em sua maioria, ao ensino e à pesquisa em cursos de graduação e pós-graduação da área.

Noronha et al. (2007) categorizaram as comunicações de docentes vinculados a PPGCI nos anais das últimas três ocorrências de eventos em $\mathrm{Cl}$, de 2000 a 2005, segundo tipos de autoria e categorias temáticas, classificadas de acordo com as linhas de pesquisa dos professores.

Em estudo bibliométrico sobre redes de colaboração científica entre os professores do Programa de Pós-Graduação em Epidemiologia da Universidade Federal de Pelotas, Maia e Caregnato (2008) analisaram as características de colaboração por meio de co-autorias dos artigos publicados em periódicos, de 1991 a 2002. O estudo revelou que os professores publicam mais artigos em autoria compartilhada do que individual e não foi encontrada relação entre aumento da produtividade e número maior de colaboradores, pois a taxa de produtividade e a taxa de autores por artigo não apresentam a mesma tendência. Ou seja, a soma de artigos publicados cresceu enquanto que o total de colaboradores permaneceu constante no período estudado. As análises de redes sociais revelaram uma configuração em torno dos professores mais produtivos.

Com o objetivo de identificar as redes sociais e intelectuais no campo da Administração da Informação, Graeml et al. (2010) analisaram os anais do Encontro Nacional da Associação Nacional de Pós-Graduação e Pesquisa em Administração (EnANPAD), 1997 a 2006, com a finalidade de levantar os relacionamentos sociais, que expressaram a existência de rede de co-autoria ainda bastante fragmentada, representada pelos principais programas brasileiros de pós-graduação na especialidade. A apreciação da estrutura de co-citações permitiu identificar as temáticas predominantes, bem como delinear a estrutura intelectual da área.

Por fim, os resultados ainda possibilitaram afirmar que as relações entre pesquisadores condicionaram suas preferências intelectuais em nível individual, e, a partir do segundo período analisado (2002-2006), esta influência passou a se dar também em nível de agrupamentos (componentes). Como observado em estudos anteriores, apesar de o número de autorias individuais ter diminuído e da média de co-autorias ter subido nos últimos três anos do período, a cooperação entre pesquisadores no campo decresceu, não acompanhando a expansão da área, o que evidencia que nem sempre o aumento de artigos co-autorados é sinônimo de aumento da cooperação. Pode-se especular que esse decréscimo na cooperação decorra do crescente número de entrantes na área, o que abrange cerca de $76 \%$ dos autores de artigos em eventos.

Para descreverem a evolução da produção de 20 títulos de periódicos científicos brasileiros das áreas de Arquivologia, Biblioteconomia, Ciência da Informação e Documentação (1972-2006), Vilan Filho e Souza e Mueller (2008) utilizam como fonte os registros artigos de periódicos científicos. Apresentam séries históricas de dados absolutos e percentuais relacionados com número de artigos publicados, de artigos em autoria múltipla (co-autoria), de títulos de periódicos, além de número médio de artigos por periódico. 
Os autores supracitados concluem que a média anual de produção brasileira foi de 175 artigos (2000-2006); a produtividade média anual, de 16 artigos / ano / título de periódico (2000-2006); o percentual de artigos em coautoria em 2006 (49,16\%) está próximo do índice de artigos em autoria única (50,84\%); e $85 \%$ dos textos em co-autoria são assinados por dois ou três autores (1972-2006). A produção inicia com 35 artigos, no ano de 1972, e chega a 179, em 2006. Pode-se notar, claramente, a redução gradativa dos valores alusivos à autoria única, que desce de $88,57 \%$ (em 1972) para 50,84\%, em 2006, correspondendo ao aumento dos percentuais de autoria múltipla, que iniciam com $11,43 \%$ e chegam a $49,16 \%$ no mesmo período. Em relação aos índices por tipo de autoria múltipla, as autorias em dupla (A2) ocorrem, de início, com percentagens elevadas (100\%, em 1972). Estas diminuem, pouco a pouco, aproximando-se da metade do total de autorias múltiplas $(56,8 \%)$, em 2006, ao passo que os valores relativos a artigos com três ou mais autores apresentam valores bem mais modestos.

A metodologia e os resultados preliminares de uma análise de rede social representando a co-autoria na área de $\mathrm{Cl}$ no Brasil são apresentados como parte do projeto RedeCl, indicando baixos níveis de concentração de artigos com autoria única e de autores transientes, segundo a Lei de Lotka e índices de centralidade na Rede com baixo índice de correlação entre si (PARREIRAS et al., 2006).

Os estudos analisados revelam semelhanças relativas ao nível de coautoria, com nítida elevação nos últimos anos. Por outro lado, não há necessária relação direta entre aumento de produtividade e maior número de trabalhos em colaboração.

\section{COLABORAÇÃO CIENTÍFICA NA PÓS-GRADUAÇÃO EM CIÊNCIA DA INFORMAÇÃO, BRASIL}

Para se representar a prática concreta da colaboração científica, foi necessária a identificação dos docentes e dos Programas brasileiros de PósGraduação em Ciência da Informação. Para tanto, criou-se uma base de dados denominada PesquisadoresCl ambientada num site da internet. Apesar da constatação de irregularidade na atualização do Lattes de alguns pesquisadores e da conseqüente defasagem entre produção e registro, esta Plataforma foi selecionada, uma vez que sua alimentação é de responsabilidade dos próprios autores.

A produção de cada pesquisador foi levantada automaticamente pelo sistema por meio do cadastro do link de cada um dos 156 pesquisadores no Lattes, categorizando-se cada um dos trabalhos por tipo de produção e coautoria. Mediante os dados coletados, analisou-se pequena amostra para verificar sua confiabilidade, o que possibilitou a análise de corpus com significativa massa de dados que representam as produções científicas de 156 professores, com 12.072 trabalhos publicados entre 1990 e 2009, assim distribuídos: 816 livros; 1.679 capítulos de livros; 3.497 artigos de periódicos e 6.080 comunicações em congressos. 
Em relação aos aspectos autorais, observou-se que a autoria múltipla predominou em 54\% do total das contribuições registradas nos últimos 20 anos. $O$ percentual de autoria múltipla representou 57\%, entre os livros; $44 \%$, entre capítulos de livros; $46 \%$, para artigos científicos; e $61 \%$, no caso de trabalhos completos apresentados em eventos. A análise diacrônica do período estudado permitiu observar que, nos dois primeiros qüinqüênios, a autoria única prevaleceu. No terceiro, registrou-se equilíbrio na distribuição do tipo de autoria, enquanto, no quarto, a autoria múltipla predomina, com $65 \%$ do total das produções. Aliás, esta distribuição coincide com os resultados de estudos anteriores que demonstram a tendência de crescimento gradual da colaboração entre autores, com destaque para o de Vilan Filho e Souza e Mueller (2008) sobre corpus similar.

O Gráfico 1 apresenta a produção de trabalhos dos docentes vinculados aos PPGCl no Brasil. Há visível crescimento desde 1994, com a observação de que a produção aumenta consideravelmente ao longo dos anos. Na análise direta dos números, é difícil mensurar a representação gráfica e a análise diacrônica dos resultados. Por este motivo, optou-se em construir gráficos que representam a relação percentual da produção em autoria única e múltipla referente a cada ano.

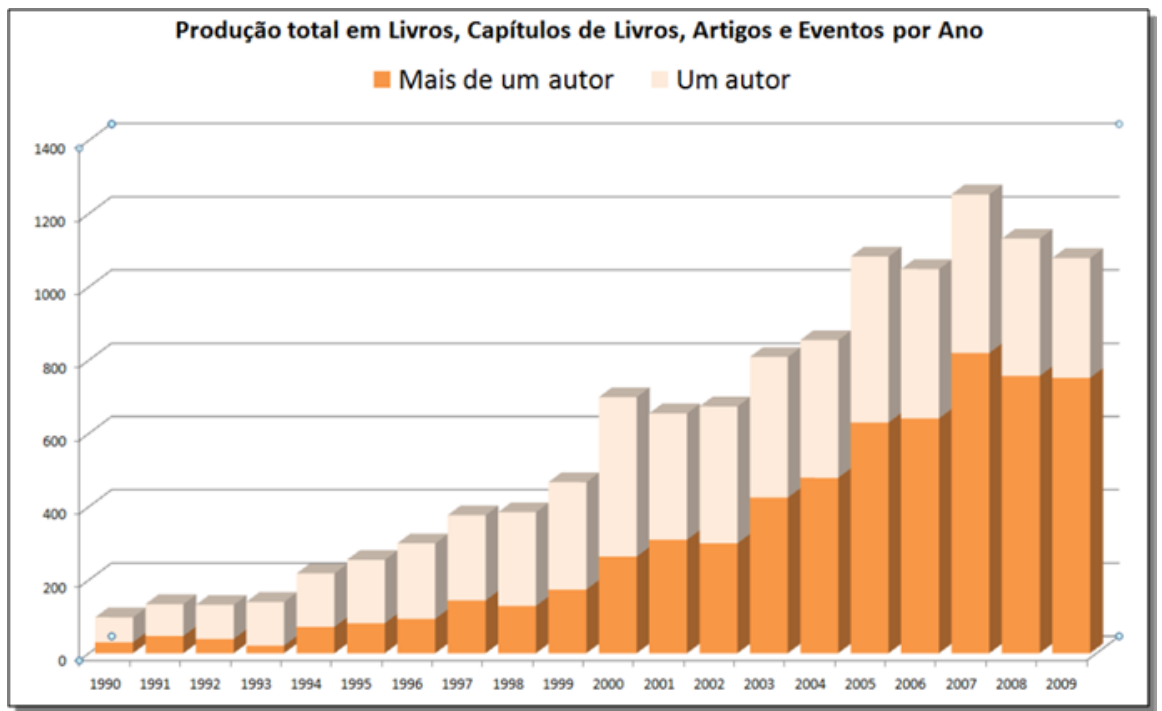

Gráfico 1 - Co-autoria na pós-graduação em Ciência da Informação por tipos de materiais

Um fato que merece destaque é a institucionalização de grupos de pesquisa pelo CNPq, em 1992, favorecendo a colaboração científica por aproximação e afinidade de temas, linha de pesquisa ou projeto científico, o que se percebe diante do crescimento da produção científica em geral, assim como em trabalhos em co-autoria.

Com relação especificamente aos livros, a participação de mais de um autor tornou-se efetiva a partir de 2005, conforme se vê no Gráfico 2. Resta salientar que, neste tipo de publicação, ocorre, de fato, colaboração de autores na produção da obra no todo e não em capítulos individuais. Entretanto, sem dúvida, as coletâneas representam a conjugação de esforços para a organização de um conjunto de trabalhos acerca de uma temática ou mais, em capítulos de distintos profissionais. Isto fica evidente quando se analisa o Gráfico 3, relativo à produção de capítulos de livros, com índice menor de co-autoria no mesmo período. 
Organizados em torno de uma temática específica, essas obras reúnem capítulos sob pontos de vista diversos e os colaboradores são convidados a escrever os textos para sua composição, o que favorece a autoria única dos capítulos, embora a obra seja coletiva.

O universo relativo aos capítulos de livros demonstra, ainda, a predominância de autoria única até o final da década de 2000, mais especificamente, ano 2007, quando a autoria múltipla desponta, embora com pouca diferença em relação à autoria única.

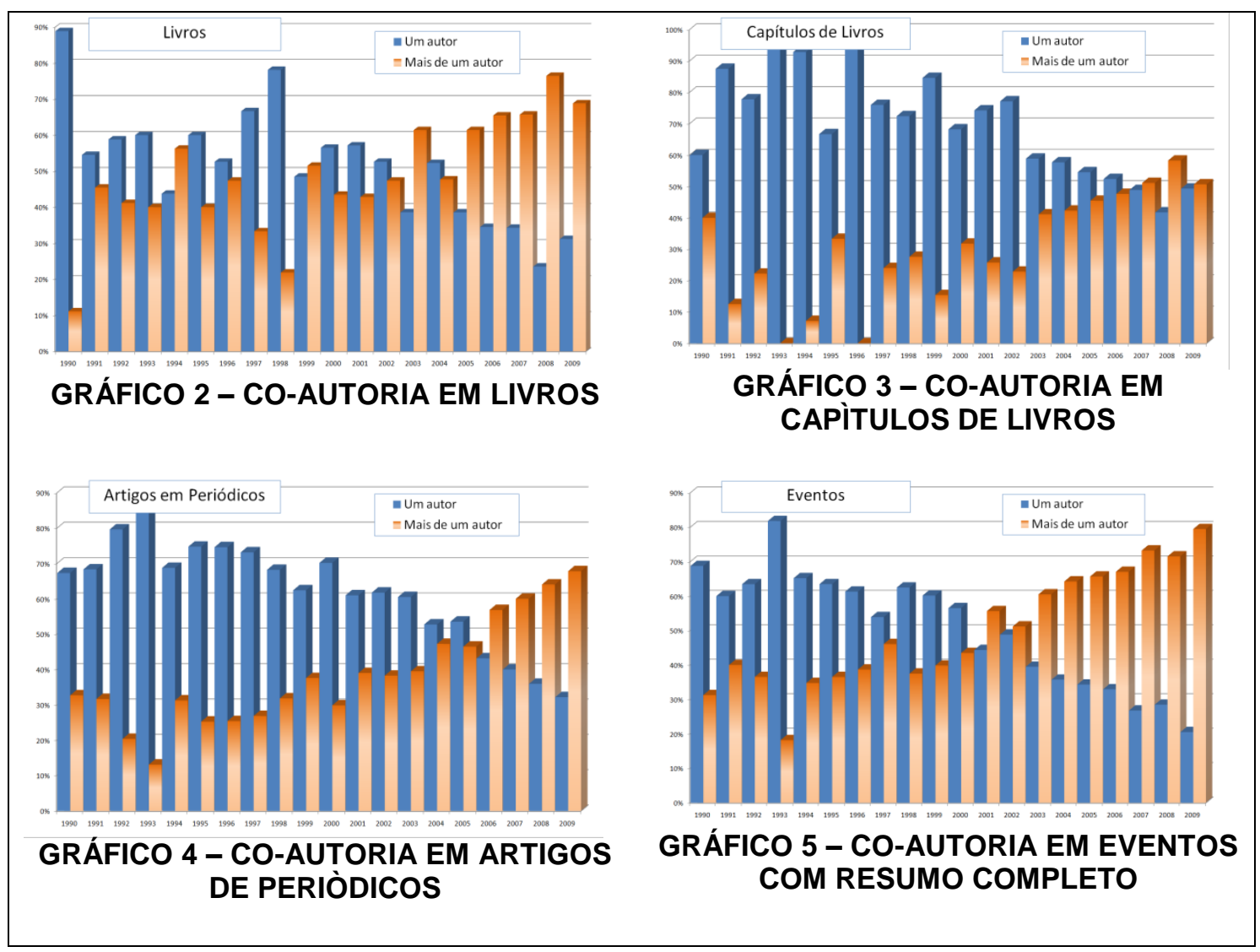

Com relação à publicação de artigos em periódicos (Gráfico 4), a quantidade de co-autoria é superior à de autoria única somente a partir do ano de 2006, e, visualmente, nota-se que a tendência de crescimento se inicia em 1997. Ao analisarem a literatura científica em artigos na área de $\mathrm{Cl}$ até 2006, Vilan Filho e Souza e Mueller (2008) também identificaram o crescimento da co-autoria nos artigos, porém com pequena divergência do ano em que a co-autoria ultrapassou a autoria única.

No Gráfico 4, percebe-se, sim, tendência de crescimento da co-autoria na Ciência da Informação, porém não se pode estimar o percentual real da colaboração científica. Entretanto, para algumas áreas, o número de publicações em co-autoria já é possível de ser expresso, como demonstra o estudo de Funaro (2010) que, na área de Odontologia, apresenta índice de co-autoria de 99,5\%, sendo somente $0,5 \%$ referente à autoria única. 
Os eventos científicos (Gráfico 5) demonstram a antecipação da tendência da cooperação em co-autoria. A primeira vez que o número de co-autorias ultrapassou a autoria única já ocorre em 2001, mantendo crescimento até o final da análise. Como descreve Meadows (1999), na comunicação científica, os primeiros resultados das pesquisas são apresentados em eventos. Somente após seu amadurecimento, a comunicação se transforma em artigo científico e, posteriormente, em livro. A análise do Gráfico 5 sugere que a evidência de coautoria se antecipou no tempo em relação à expressão da produção científica em periódicos.

Acredita-se que a análise diacrônica dos gráficos alusivos aos livros, capítulos de livros, artigos científicos e eventos confirma os conceitos de Meadows (1999) no que se refere ao processo de comunicação científica. Sugere, ainda, que o fenômeno da co-autoria segue a mesma lógica da comunicação científica como um todo: parte dos eventos e evolui até a redação de artigos científicos ou de livros.

\section{CONSIDERAÇÕES FINAIS}

A análise do currículo Lattes dos pesquisadores dos Programas de PósGraduação em Cl, Brasil, demonstra o crescimento gradativo na participação da publicação em co-autoria, indicando maior interação entre os grupos de pesquisadores. E mais, observa-se que a tendência de crescimento ocorre em todas as categorias de textos, porém, mais precocemente e com maior incidência, em comunicações de eventos científicos e em artigos de revistas.

De qualquer forma, a constatação de que a produção em co-autoria, no Brasil, vem crescendo gradativamente, não dispensa análises sobre dados empíricos contemplando outras variáveis. Também merecem estudos as premissas de que a co-autoria resulta da cooperação científica ou se visa tãosomente à comprovação de produção dos pesquisadores em $\mathrm{Cl}$ como meio de atender critérios de avaliação das instituições nacionais de fomento. Isto porque, se percebe uma estrutura de relações de produção, na qual instrumentos de avaliação objetiva vem indicando tendências, de modo que é possível desvendar razões, determinações e fatores que influenciam a atividade e o capital científicos.

É possível, ainda, observar as articulações entre formas de produção e comunicação adotadas pelos pesquisadores e o contexto em que se produzem e reproduzem os conhecimentos, promotor de políticas de apoio e fomento à produção científica nas instituições.

\section{REFERÊNCIAS}

ALVES, V. B. A. Open Archives: via verde ou via dourada? Ponto de Acesso, Salvador, v. 2, n. 2, p. 127-137, ago. / set. 2008.

ARAúJO, C. A. A. Correntes teóricas da Ciência da Informação. Ciência da Informação, Brasília, DF, v. 38, n. 3, p. 192-204, set. / dez. 2009. 
ARGAÑARAZ, E. B.; SOSA, A. C.; RAPELA, M. V. Análisis bibliométrico de la producción científica de los investigadores con proyectos aprobados por la Secretaría de Ciencia y Tecnología de la Universidad Nacional de Córdoba: 19961999. TransInformação, Campinas, v. 15, n. 2, p. 231-243, maio / ago. 2003.

ARGOLLO, R. V. et al. Web 2.0 como estruturante dos processos de produção e difusão científica em um grupo de pesquisa: o TWiki e o GEC. Perspectivas em Ciência da Informação, Belo Horizonte, v. 15, n. 1, p. 118-131, jan. / abr. 2010.

BARBOSA, J. S.; SILVA, L. C. O.; SILVA, H. O. P. A recuperação de informação em trabalhos apresentados em encontros nacionais e regionais de estudantes de Biblioteconomia, Documentação, Ciência e Gestão da Informação: uma proposta de utilização do programa Open Conference Systems. Biblos: Revista do Departamento de Biblioteconomia e História, Rio Grande, v. 23, n. 2, p. 9-22, 2009.

BASE BRASILEIRA DE ARTIGOS DE PERIÓDICOS CIENTÍFICOS EM CIÊNCIA DA INFORMAÇÃO. Versão 0.01.14. Curitiba: UFPR, 2009-2010. Disponível em: <http:// www.brapci.ufpr.br/index.php> Acesso em: 28 abr. 2010.

BEAVER, D. D. Reflections on scientific collaboration (and its study): past, present, and future. Scientometrics, Budapest, v. 52, n. 3, p. 365-377, 2001.

BERTIN, P. Proposta de modelo trifásico para a evolução da comunicação científica: dos primeiros periódicos impressos ao sistema de comunicação eletrônica atual. TransInformação, Campinas, v. 20, n. 1, p.17-28, jan. / abr. 2008.

BOMFÁ, C. R. Z. et al. Acesso livre à informação científica digital: dificuldades e tendências. TransInformação, Campinas, v. 20, n. 3, set. / dez. 2008.

BOURDIEU, P. A economia das trocas simbólicas. São Paulo: Perspectiva, 1976.

CAXIAS, R. S. Das tecnologias da informação à comunicação científica: críticas à nova cultura da pesquisa em educação. Em Questão, Porto Alegre, v. 14, n. 2, p. 301-315, jul. / dez. 2008.

CONSELHO NACIONAL DE DESENVOLVIMENTO CIENTÍFICO E TECNOLÓGICO. Plataforma Lattes. Brasília, DF, [2008]. Disponível em: $<$ http://lattes.cnpq.br/>. Acesso em: 27 jul. 2010.

COSTA, S. Abordagens, estratégias e ferramentas para o Acesso Aberto via periódicos e repositórios institucionais em instituições acadêmicas brasileiras. Liinc em Revista, Rio de Janeiro, v. 4, n. 2, p. 218-232, set. 2008.

CUMBERS, A.; MACKINNON, D.; CHAPMAN, K. Innovation, collaboration, and learning in regional clusters. Environment and Planning A. London, v. 35, p. 16891706, 2003. 
DE LANGE, C; GLÄNZEL, W. Modeling and measuring multilateral co authorship in international scientific collaboration. Part 1. Development of a new model using a series expansion approach. Scientometrics, Budapest, v. 40, n. 3, p. 593-604, Nov. / Dec. 1997.

DUARTE, E. N. et al. Estratégias metodológicas adotadas nas pesquisas de iniciação científica premiadas na UFPB. Encontros Bibli: Revista Eletrônica de Biblioteconomia e Ciência da Informação, Florianópolis, v. 14, n. 27, p. 170-190, 2009.

FORESTI, N. A. B.; MARTINS, M. S. M. Revistas brasileiras de Biblioteconomia, Documentação e Ciência da Informação: produtividade de autores no período de 1980 a 1985. Revista da Escola de Biblioteconomia da UFMG, Belo Horizonte, v. 16, n. 1, p. 54-71, mar. 1987.

FUNARO, V. M. B. de O. Rede colaborativa entre autores em Odontologia: docentes dos Programas de Pós-Graduação credenciados em universidades participantes do Sistema de Informação Especializado na Área de Odontologia (SIEO). 2010. 184 f. Tese (Doutorado em Ciência da Informação) - Escola de Comunicações e Artes, Universidade de São Paulo, São Paulo. 2010.

GONZÁLEZ DE GÓMEZ, M. N.; MACHADO, R. A ciência invisível: o papel dos relatórios e as questões de acesso à informação científica. DataGramaZero, v. 8, n. 5, out. 2007.

GRAEML, A. R. et al. Redes sociais e intelectuais na área de pesquisa em administração da informação: uma análise cientométrica do período 1997-2006. Informação \& Sociedade: Estudos, João Pessoa, v. 20, n. 1, p.95-110, jan. / abr. 2010.

KATZ, J. S.; MARTIN, B. R. What is research collaboration? Research Policy, Amsterdam, v. 26, p. 1-18, 1997.

LADRIÈRE, J. Filosofia e práxis científica. Rio de Janeiro: F. Alves, 1978.

LEE, S.; BOZEMAN, B. The impact of research collaboration on scientific productivity. Social Studies of Science, [S. I.], v. 35, n. 5, p. 673-702, 2005.

LETA, J. ; CRUZ, C. H. B. A produção científica brasileira. In: VIOTTI, E. B.; MACEDO, M. M. (Org.). Indicadores de ciência, tecnologia e inovação no Brasil. Campinas: Unicamp, 2003. p. 121-168.

LIMA, R. A.; VELHO, L. M. L. S.; FARIA, L. I. L. Indicadores bibliométricos de cooperação científica internacional em bioprospecção. Perspectivas em Ciência da Informação, Belo Horizonte, v. 12, n. 1, p. 50-64, jan. / abr. 2007.

LLOYD, C. As estruturas da história. Rio de Janeiro: Zahar, 1995. 
MAIA, M. F.; CAREGNATO, S. E. Co-autoria como indicador de redes de colaboração científica. Perspectivas em Ciência da Informação, Belo Horizonte, v. 13, n. 2, p. 18-21, maio / ago. 2008.

MATTHIESSEN, C. W.; SCHWARZ, A. W.; FIND, S. The top-level global research system, 1997-99: centers, network and nodality. An analysis based on bibliometric indicators. Urban Studies, Essex, v. 39, n. 5-6, p. 903-927, 2002.

MEADOWS, A. J. A comunicação científica. Brasília, DF: Briquet Lemos Livros, 1999.

MOURA, M. A. Informação e conhecimento em redes virtuais de cooperação científica: necessidades, ferramentas e usos. DataGramaZero, v. 10, n. 2, abr. 2009.

MUELLER, S. P. M. O estudo do tema comunicação científica e tecnológica no Brasil: tendências e perspectivas na área de Ciência da Informação. Tendências da Pesquisa Brasileira em Ciência da Informação, Belo Horizonte, v. 1, n. 1, jan. / dez. 2008.

NARIN, F.; STEVENS, K.; WHITLOW, E. S. Scientific co-operation in Europe and the citation of multinationally authored papers. Scientometrics, Budapest, v. 21, n. 3, p. 313-323, 1991.

NEDERHOF, A. J. et al. Assessing the usefulness of bibliometric indicators for the humanities and the social and behavioral sciences: a comparative study. Scientometrics, Budapest, v. 15, n. 5-6, p. 423-435, 1989.

NEDERHOF, A. J. et al. Research performance indicators for university departments: a study of an agricultural university. Scientometrics, Budapest, v. 27, n. 2, p. 157-178, 1993.

NEDERHOF, A. J.; MOED, H. F. Modeling multinational publication: development of an on-line fractionation approach to measure national scientific output. Scientometrics, Budapest, v. 27, p. 39-52, 1993.

NEDERHOF, A. J; NOYONS, E. C. M. International comparison of department's research performance in the Humanities. Journal of the American Society for Information Science and Technology, Maryland, v. 43, n, 3, p. 249-256, 1992.

NEDERHOF, A. J.; VAN RAAN, A. F. J. A bibliometrics analysis of six economics research groups: a comparison with peer review. Research Policy, Amsterdam, v. 22, p. 353-368, 1993.

NEDERHOF, A. J.; ZWAAN, R. A. Quality judgment of journals as indicators of research performance in the humanities and the social and behavioral sciences. Journal of the American Society for Information Science and Technology, Maryland, v. 42, n. 5, p. 332-340, 1991. 
NORONHA, D. P. et al. Comunicações em eventos da área da Ciência da Informação: contribuição dos docentes dos Programas de Pós-Graduação. Encontros Bibli: Revista Eletrônica de Biblioteconomia e Ciência da Informação, Florianópolis, v. 12, n. 23, p. 171-193, 1ํsem. 2007.

NORONHA, D. P.; MARICATO, J. M. Estudos métricos da informação: primeiras aproximações. Encontros Bibli: Revista Eletrônica de Biblioteconomia e Ciência da Informação, Florianópolis, v.13, p. 116-128, $1^{\stackrel{0}{ }}$ sem. 2008. Edição especial.

OHIRA, M. L. B.; OHIRA, M. Seminário Nacional de Bibliotecas Universitárias SNBU (2000-2004): análise das citações. Encontros Bibli: Revista Eletrônica de Biblioteconomia e Ciência da Informação, Florianópolis, v. 13, n. 25, p. 136-155, 1ํsem. 2008.

OLIVEIRA, M. Grupos de pesquisa em Ciência da Informação no Brasil. Tendências da Pesquisa Brasileira em Ciência da Informação, Belo Horizonte, v. 2, n. 1, p. 38-59, jan. / dez. 2009.

OLIVEIRA, E. F. T.; FERREIRA, K. E. Fontes de informação on-line em Arquivologia: uma avaliação métrica. Biblos: Revista do Departamento de Biblioteconomia e História, Rio Grande, v. 23, n. 2, p. 69-76, 2009.

PARREIRAS, F. S. et al. REDECl: colaboração e produção científica em Ciência da Informação no Brasil. Perspectivas em Ciência da Informação, Belo Horizonte, v. 11, n. 3, p. 302-317, set. / dez. 2006.

PERSSON, O.; GLÄNZEL, W.; DANELL, R. Inflationary bibliometric values: the role of scientific collaboration and the need for relative indicators in evaluative studies. Scientometrics, Budapest, v. 60, n. 3, p. 421-432, 2004.

RIBEIRO, O. B.; VIDOTTI, S. A. B. G. Otimização do acesso à informação científica: discussão sobre a aplicação de elementos da arquitetura da informação em repositórios digitais. Biblos: Revista do Departamento de Biblioteconomia e História, Rio Grande, v. 23, n. 2, p. 105-116, 2009.

RUSSELL, J. M.; DEL RÍO, A.; CORTÉS, H. Highly visible science: a look at three decades of research from Argentina, Brazil, Mexico and Spain. Interciencia, Caracas, v. 32, n. 9, Sep. 2007.

SANCHO, R. et al. Indicadores de colaboración científica inter-centros en los países de América Latina. Interciencia, Caracas, v. 31, n. 4, Apr. 2006.

SAVANUR, K.; SRIKANTH, R. Modified collaborative coefficient: a new measure for quantifying the degree of research collaboration. Scientometrics, Budapest, 2009.

SWAN, A. Why Open Access for Brazil? Liinc em Revista, Rio de Janeiro, v. 4, n. 2, p. 158-171, set. 2008. 
TARGINO, M. G. A região geográfica como fator interveniente na produção de artigos de periódicos científicos. In: MUELLER, S. P. M.; PASSOS, E. J. (Org.). Comunicação científica. Brasília, DF: UnB, 2000. p. 51-72.

VALERIO, P. M.; PINHEIRO, L. V. R. Da comunicação científica à divulgação. TransInformação, Campinas, v. 20, n. 2, p.159-169, maio / ago. 2008.

VANZ, S. A. S. As redes de colaboração científica no Brasil: (2004-2006). Porto alegre, 2009. 204 f. Tese (Doutorado em Comunicação e Informação) - Programa de Pós-Graduação em Comunicação e Informação, Faculdade de Biblioteconomia e Comunicação, Universidade Federal do Rio Grande do Sul, Porto Alegre. 2009.

VANZ, S. A. S.; STUMPF, I. R. C. A colaboração internacional no ISI: panorama dos artigos brasileiros nos anos 2004-2006. In: ENCONTRO NACIONAL DE PESQUISA DA ANCIB, 10. , João Pessoa, PB. Anais... João Pessoa: UFPB, 2009.

VELHO, L. A avaliação do desempenho científico. Cadernos USP, São Paulo, n. 1, p. 22-40, out. 1986.

VILAN FILHO, J. L.; SOUZA, H. B.; MUELLER, S. P. M. Artigos de periódicos científicos das áreas de informação no Brasil: evolução da produção e da autoria múltipla. Perspectivas em Ciência da Informação, Belo Horizonte, v. 13, n. 2, p.217, maio / ago.2008.

WEISZ, J.; ROCO, M. C. Redes de pesquisa e educação em engenharia nas Américas. Rio de Janeiro: Finep, 1996.

WHITLEY, R. Cognitive and social institutionalization of scientific specialities and research areas. In: WHITLEY, R. (Ed.). Social processes of scientific development. London: Routledge and Kegan, 1974. p. 69-95.

ZITT, M.; BASSECOULARD, E.; OKUBO, Y. Shadows of the past in international cooperation: collaboration profiles of the top five producers of science. Scientometrics, Budapest, v. 47, p. 627-657, 2000.

Title

Co-authorship practices in the scientific communication in postgraduate studies on Information Science in Brazil.

\section{Abstract}

This article performs a diachronic analysis of 20 years (1990-2009) of the scientific production of researchers linked to stricto sensu postgraduate programs in Information Science in Brazil, focusing on co-authorship production. It composes a specific corpus, with Brazilian scientific articles in this area, which are related to the scientific communication, particularly emphasizing co-authorship. It executes an empiric analysis on the production from researchers, as raised from Lattes Platform curricula, specifying coauthorship cases in the production of books, book chapters, journal articles and research works submitted in events. It presents the results of an analysis of 12,072 scientific works 
from 156 researchers, in order to put in evidence the route followed during the evolutive process of co-authoring in publications in this field, identifying the growth and expansion of the co-authorship process, which is still in evolution.

\section{Keywords}

Communication of science. Scientific communication. Information Science. Coauthorship.

\section{Título}

Prácticas de coautoría en el proceso de comunicación científica en Ciencia de la Información en Brasil.

\section{Resumen}

Analiza diacrónicamente 20 años (1990-2009) de la producción científica de los investigadores vinculados a los estudios de postgrado en Ciencias de la Información en Brasil, centrándose en la producción en coautoría. Constituye un corpus específico, con una revisión de artículos brasileños científicos en el área en relación con el tema comunicación científica, enfatizando en la coautoría. Lleva a cabo un análisis empírico sobre la producción de los investigadores registrada en el currículo Lattes, especificando los casos de coautoría en la producción de libros, capítulos de libros, artículos en revistas científicas y ponencias en eventos. Presenta los resultados de los análisis de 12.072 artículos científicos de 156 investigadores para mostrar la trayectoria del proceso evolutivo de la producción en coautoría en las publicaciones de la zona, identificando el crecimiento y expansión de la producción en coautoría.

\section{Palabras clave}

Comunicación de la ciencia. Comunicación científica. Ciencia de la Información. Coautoría.

Recebido em: 15/03/2010

Aceito em: 15/09/2010 